\title{
Phenolic Profile and Antioxidant Capacity of Selected Medicinal and Aromatic Plants: Diversity upon Plant Species and Extraction Technique
}

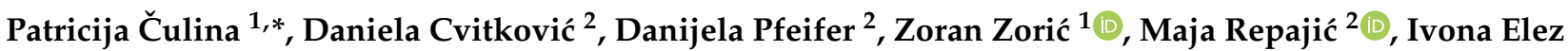 \\ Garofulić $^{2}$, Sandra Balbino ${ }^{2}$ and Sandra Pedisić ${ }^{1}$ \\ 1 Faculty of Food Technology and Biotechnology, University of Zagreb P. Kasandrića 3, 23000 Zadar, Croatia; \\ zzoric@pbf.hr (Z.Z.); sandra.pedisic@pbf.unizg.hr (S.P.) \\ 2 Faculty of Food Technology and Biotechnology, University of Zagreb Pierottijeva 6, 10000 Zagreb, Croatia; \\ dcvitkovic@pbf.hr (D.C.); dpfeifer@pbf.hr (D.P.); maja.repaji@@pbf.unizg.hr (M.R.); \\ ivona.elez@pbf.unizg.hr (I.E.G.); snedjer@pbf.hr (S.B.) \\ * Correspondence: plisica@pbf.hr
}

check for updates

Citation: Čulina, P.; Cvitković, D.; Pfeifer, D.; Zorić, Z.; Repajić, M.; Elez Garofulić, I.; Balbino, S.; Pedisić, S. Phenolic Profile and Antioxidant Capacity of Selected Medicinal and Aromatic Plants: Diversity upon Plant Species and Extraction Technique. Processes 2021, 9, 2207. https://doi.org/10.3390/pr9122207

Academic Editor: Irena Zizovic

Received: 15 November 2021 Accepted: 7 December 2021

Published: 7 December 2021

Publisher's Note: MDPI stays neutral with regard to jurisdictional claims in published maps and institutional affiliations.

Copyright: (c) 2021 by the authors. Licensee MDPI, Basel, Switzerland. This article is an open access article distributed under the terms and conditions of the Creative Commons Attribution (CC BY) license (https:// creativecommons.org/licenses/by/ $4.0 /)$.

\begin{abstract}
Phenolic content and antioxidant capacity (AC) was evaluated in extracts of bay, sage and thyme leaves, myrtle leaves and berries, and sea buckthorn berries obtained by conventional (CE) and advanced extraction techniques [ultrasound-assisted (UAE) and accelerated solvent extraction (ASE)] using $80 \%$ acetone $(v / v)$ as extraction solvent. Extracts were analyzed for phenolic content using UPLC/ESI MS ${ }^{2}$ and AC by ORAC method. Results indicated the variations in the phenolic composition and concentrations among analyzed plant species and applied extraction methods. Flavonoids showed to be the predominant phenolic group represented by flavonols kaemferol-3-Ohexoside (182.58-321.45 mg 100-1 $\mathrm{g} \mathrm{dm}$ ) and quercetin-3-glucoside (253.05-315.67 mg/100 g dm) in bay leaves, by flavonol isorhamnetine-3-O-hexoside $(27.76-45.16 \mathrm{mg} / 100 \mathrm{~g} \mathrm{dm}$ ) in sea buckthorn berries and by flavone luteolin-7-O-glucoside $(470.27-781.78 \mathrm{mg} / 100 \mathrm{~g} \mathrm{dm})$ in sage leaves. Among the phenolic acids, hydroxybenzoic acids and their derivates were the predominant phenolic group in thyme leaves and myrtle. Statistical analysis showed that ASE contributed to the highest content of total flavonols, flavones, hydroxycinnamic and hydroxybenzoic acids as well as AC. CE was more efficient method for the extraction of total flavan-3-ols, while UAE showed the highest efficiency in extraction of total anthocyanins. Analyzed plant extracts proved to be a rich source of various phenolics and results indicated suitable extraction methods for target phenolic compounds characteristic for certain plant species.
\end{abstract}

Keywords: ultrasound assisted extraction; accelerated solvent extraction; agitation-assisted extraction; bay; thyme; myrtle; sage; sea buckthorn; phenolics; oxygen radical absorbance capacity

\section{Introduction}

The medicinal and aromatic plants (MAP) are widely used for culinary purposes to improve the taste and other organoleptic properties as well as in traditional medicine due to their capacity to promote health [1]. Among the numerous MAP, sage (Salvia officinalis L.) and thyme (Thymus vulgaris L.) as powerful members of the Lamiaceae family, bay (Laurus nobilis L.) as a member of Lauraceae family and myrtle (Myrtus communis L.) as a member of Myrtaceae are among the most commonly used plants in traditional Mediterranean remedies. Moreover, sea buckthorn (Hippophae rhamnoides L.), as a member of family Elaegnaceae, is used in oriental traditional medicine mainly for the treatment of lung, skin and gastrointestinal problems and inflammation [2-5].

These plant species differ in their botanical and morphological characteristics. For example, sage is a perennial, evergreen subshrub, with woody stems, grayish leaves, and blue to purplish flowers. A low-growing hardy perennial, thyme is a fragrant herb 
with small and oval gray-green leaves, thin, woody stems and tiny pink, tubular flowers. Bay tree is an evergreen with the thick leathery and glossy dark green colored leaves. Myrtle as an evergreen shrub or a small tree is covered by branches, small leaves and starry, scented, white or pink flowers, whereas blue-black berry fruits are small, round shape with seeds inside. Sea buckthorn is a small shrub with a distinct pale silvery-green, lanceolate leaves and orange-yellow globose to egg-shaped berries. Although listed plants have a unique composition, the health benefits they provide originate primarily from bioactive compounds, particularly phenolics and essential oils volatiles. These compounds possess antioxidant, antimicrobial, anti-inflammatory, anticancer, antiviral and antidiabetic effects [6]. Content of phenolics and their molecular structure considerably influence the pharmacological properties of MAP [7]. In particular, the leaves of MAP have been reported to contain higher levels of phenolic compounds and antioxidant activity when compared to berries. However, phenolic content in berries and leaves varies depending on the species, geographical location and the degree of physiological maturity $[8,9]$. The main phenolic compounds determined in sage and thyme are phenolic acids such as rosmarinic acid, methyl rosmarinate, caffeic acid, cinnamic acid, chlorogenic acid and quinic acid besides flavonoids such as apigenin, luteolin and quercetin [10]. Myrtle leaves and berries are considered as a good source of phenolic acids such as caffeic, ellagic and gallic acid derivates, flavonoids quercetin, catechin, myricetin derivates and anthocyanins in colored berries [11]. The major phenolic compounds found in bay leaves extracts are flavonoids quercetin, kaempferol, rutin, and their derivates as well as phenolic acids such as rosmarinic and caffeic acid, respectively [12]. On the other hand, sea buckthorn berries and leaves are considered to be abundant with flavonol glycosides of isorhamnetin, kaempferol and quercetin derivates $[3,4]$.

Extraction of bioactive compounds is the first step in the analysis of MAP and it plays a crucial role in their further separation and characterization [13]. Currently, there is a considerable rise on the application of MAP extracts as functional ingredients in food and beverage commodities since they present natural, eco-friendly and generally recognized as safe products. Good quality in extract production requires high quality of the raw plant material as well as the appropriate extraction procedure and conditions [14-16]. Due to different morphological and botanical characteristics of the above-mentioned MAP, it is important to modify the extraction method in order to obtain higher yields of the target compounds and the lowest possible proportion of ballast substances. In most cases, solid-liquid extraction can be advantageously used for the recovery of natural compounds from untreated or pretreated biomass materials $[17,18]$. The most commonly used method for the extraction of phenolic compounds from MAP is conventional extraction using heat or stirring and solvents such as water and polar organic solvents (methanol, ethanol or acetone) or their aqueous mixtures $[19,20]$. Crude phenolic extracts contain complex mixtures of some classes of phenols, which are selectively soluble in the different solvents. According to Dai and Mumper [14], alcohols have been found to be more efficient in extraction of lower molecular weight polyphenols, while acetone is more effective for extraction of higher molecular weight polyphenols. Acetone is a useful extraction solvent, which is highly effective at extracting antioxidants and it is able to dissolve many hydrophilic and lipophilic components. It is widely used for the extraction of tannins and phenolic compounds [16]. According to literature data, acetone showed better extractability of total phenolics from millets grown in India than methanol and water [21] while aqueous acetone $(80 \% v / v)$ showed as the most effective for the extraction of total flavonoids in baobab [22]. However, advanced extraction techniques have been increasingly explored in recent years in order to improve the extraction efficiency of bioactive compounds and to overcome the disadvantages of conventional extractions such as large solvent consumption, long extraction time and high energy use [20,23]. Some of the most promising methods are ultrasound-assisted extraction (UAE), microwave-assisted extraction (MAE), supercritical fluid extraction (SCFE) and accelerated solvent extraction (ASE) [20,24-27]. The UAE is based on the principle of cavitation (production, growth and collapse of bubbles in the 
extraction solvent and sample material), while MAE occurs as the result of changes in the cell structure caused by electromagnetic waves. ASE uses high pressure to keep solvents liquid above their boiling point which facilitates the extractability of the analytes and SCFE employs supercritical fluids as solvent for the extraction of bioactive compounds $[14,28,29]$. Extraction efficiency of conventional and advanced extraction techniques generally depends on the selection of critical input parameters [29]. The data regarding phenolic content in different plants are difficult to compare since the same extraction conditions can provide different yields of phenolics due to complex nature of sample matrix and differences in plant morphological properties, chemical composition and undesirable ballast content.

Among the broad range of extraction techniques, UAE and ASE have been widely used in the extraction of various phenolic compounds from different parts of MAP without causing significant changes in the structural and functional properties of the target compounds $[14,20,25,27]$. According to literature data, during UAE temperature and extraction time considerably vary due to sample composition, while solvent type and temperature are the most significant parameters in ASE [30].

Numerous desirable biological effects originating from MAP, such as antioxidant properties, may considerably depend on the amount and composition of isolated phenolic compounds. Phenolic compounds act through several chemical mechanisms as reducing agents, hydrogen donors, singlet oxygen quenchers and metal chelators [31]. Generally, total phenolic content is highly correlated with the antioxidant capacity and leaves have higher antioxidant capacity in comparison with fruits [26,32]. The most frequently used in vitro model for measuring antioxidant capacity in MAP extracts is oxygen radical absorption capacity (ORAC) assay since it is relevant to in vivo conditions $[33,34]$.

Although UAE and ASE of phenolics have been studied for particular MAP species, studies on phenolic extraction from bay, sage and thyme leaves, myrtle leaves and berries, and sea buckthorn berries are scarce. Therefore, the aim of this study was to compare the efficiency of conventional (CE) and advanced extraction methods (UAE and ASE) in the isolation of different classes of phenolic compounds in selected plant species which differ in botanical and morphological characteristics (sage, thyme, bay, myrtle and sea buckthorn). Moreover, biological potential of obtained extracts was also evaluated by determining the antioxidant capacity using ORAC method.

\section{Materials and Methods}

\subsection{Chemicals}

All used chemicals were analytical grade. Acetone was purchased from T.T.T. d.o.o. (Sveta Nedjelja, Croatia), acetonitrile from Honeywell (Seelze, Germany), formic acid from J. T. Baker (Phillipsburg, NJ, USA) and hexane from Honeywell (Seelze, Germany).

Commercial standards of phenolic compounds quercetin-3-glucoside, kaempferol3-rutinoside, myricetin, caffeic, gallic, ferulic, chlorogenic, p-coumaric, vanillic, syringic, cinnamic, synaptic and rosmarinic acid, and delphinidin chloride were purchased from Sigma-Aldrich (Steinheim, Germany). Epicatechin, catechin, epigallocatechin gallate, epicatechin gallate, procyanidin B1, procyanidin B2, apigenin and luteolin were purchased from Extrasynthese (Genay, France) and quercetin-3-rutinoside from Acros Organics (Thermo Fisher Scientific, Geel, Belgium).

\subsection{Plant Material}

Dry leaves of bay (Laurus nobilis L.), thyme (Thymus vulgaris L.) and sage (Salvia officinalis L.) were obtained from a local manufacturer Suban Ltd. (Strmec Samoborski, Croatia). Dried sea buckthorn (Hippophae rhamnoides L.) berries and leaves and berries of myrtle (Myrtus communis L.) were obtained from a local herbal manufacturer Jerkin (Zadar, Croatia). Botanical identification of plants was performed by the experts from the Faculty of Agriculture, University of Zagreb, Croatia. 


\subsection{Sample Preparation}

All plant materials were ground in commercial grinder (GT11, Tefal, France) and sieved through a 60-mesh sieve to obtain uniform particle size. Prior to extraction of phenolics, in each extraction procedure obtained powder (100 g) was defatted using nhexane at $60^{\circ} \mathrm{C}$ for $30 \mathrm{~min}$. The solid-liquid mixture was then centrifugated at $4500 \times \mathrm{g} \mathrm{rpm}$ for $15 \mathrm{~min}$ (Rotofix 32, HETTICH, Tuttlingen, Germany) and the residue was dried in an oven (FN 500, Nuve, Ankara, Turkey) at $30^{\circ} \mathrm{C}$ for $6 \mathrm{~h}$. Dried defatted powders were stored at $4{ }^{\circ} \mathrm{C}$ prior to phenolics extraction.

\subsection{Extraction of Phenolic Compounds}

\subsubsection{UAE}

A mass of defatted powder $(2.5 \pm 0.001 \mathrm{~g})$ was mixed with $40 \mathrm{~mL}$ of aqueous acetone solution $(80 \%, v / v)$ and extraction was performed in ultrasonic bath (Elmasonic $\mathrm{S} 40 \mathrm{H}$, Elma-Hans Schmidbauer GmbH \& Co. Singen, Germany) with ultrasound frequency of $37 \mathrm{kHz}$ and power of $340 \mathrm{~W}$ at $60^{\circ} \mathrm{C}$ for $30 \mathrm{~min}$. Extraction conditions were selected based on our preliminary studies on selected MAP after optimization of process variables such as sonication time (10-45 $\mathrm{min})$ and temperature $\left(30-70{ }^{\circ} \mathrm{C}\right)$ (results not yet published). The mixture was then centrifuged at $4500 \times g$ rpm for $15 \mathrm{~min}$, supernatants were filtered (Whatman No. 4) into $50 \mathrm{~mL}$ volumetric flasks, and made up to volume with extraction solvent. Extractions were performed in a duplicate $(n=2)$ and extracts were stored at $-18{ }^{\circ} \mathrm{C}$ in nitrogen gas atmosphere until analysis (not longer than 10 days). Prior to UPLC/ESI-MS2 analysis extracts were filtered through $0.45 \mu \mathrm{m}$ membrane filter (MachereyNagel GmbH, Düren, Germany).

\subsubsection{ASE}

ASE was performed using Dionex ${ }^{\mathrm{TM}}$ ASE $^{\mathrm{TM}} 350$ extractor (Thermo Fisher Scientific Inc., Sunnyvale, CA, USA) and the procedure was set according to the method by Repajić et al. [24], slightly modified: $34 \mathrm{~mL}$ stainless steel cells fitted with 2 cellulose filters (Dionex ${ }^{\mathrm{TM}}$ 350/150 Extraction Cell Filters, Thermo Fisher Scientific Inc.) at the bottom of the cells were filled with a mixture of sample $(2.5 \pm 0.001 \mathrm{~g})$ and diatomaceous earth $(0.5 \mathrm{~g})$. Extraction was conducted using aqueous acetone solution $(80 \%, v / v)$ as extraction solvent under the temperature $60^{\circ} \mathrm{C}$, static extraction time $5 \mathrm{~min}, 3$ extraction cycles and constant pressure of 10.34 MPa. After extraction, cells were flushed with solvent (50\% flushing) and purged with nitrogen for $30 \mathrm{~s}$. Obtained extracts were collected in $250 \mathrm{~mL}$ glass vial with Teflon septa, transferred into $50 \mathrm{~mL}$ volume flask and made up to volume with the extraction solvent. Extractions were performed in a duplicate $(n=2)$. Extracts were stored at $-18{ }^{\circ} \mathrm{C}$ in nitrogen gas atmosphere and analyzed in next 10 days. Prior to UPLC/ESI-MS2 analysis extracts were filtered through $0.45 \mu \mathrm{m}$ membrane filter (Macherey-Nagel $\mathrm{GmbH}$ ).

\subsubsection{CE}

CE procedure included agitation-assisted extraction as follows: $2.5 \pm 0.001 \mathrm{~g}$ of ground sample was mixed with the $80 \%$ aqueous acetone solution $(v / v, 40 \mathrm{~mL})$, and the mixture was vigorously stirred for $5 \mathrm{~min}$. Extraction was performed at $60^{\circ} \mathrm{C}$ for $30 \mathrm{~min}$, based on our preliminary studies on selected MAP after optimization of process variables such as time (20-120 $\mathrm{min}$ ) and temperature $\left(30-70{ }^{\circ} \mathrm{C}\right)$ (results not yet published), in water bath shaker (SBS40, Cole-Par-mer, Stone, UK)). The mixture was then centrifuged at $4500 \times \mathrm{g} \mathrm{rpm}$ for $15 \mathrm{~min}$ and supernatants were filtered (Whatman No. 4) into $50 \mathrm{~mL}$ volumetric flasks, and filled up with extraction solvent. Afterwards, extracts $(n=2)$ were stored at $-18{ }^{\circ} \mathrm{C}$ in nitrogen gas atmosphere until analyzed (in a period of 10 days). Extracts were filtered through $0.45 \mu \mathrm{m}$ membrane filter (Macherey-Nagel $\mathrm{GmbH}$ ) before UPLC/ESI-MS2 analysis. 


\subsection{Characterization of Phenolic Compounds by UPLC/ESI-MS ${ }^{2}$ Analysis}

The UPLC/ESI-MS ${ }^{2}$ analysis was used for characterization of phenolics using Agilent 1290 RRLC instrument (Agilent, Santa Clara, CA, USA) connected to the Agilent triple quadrupole mass spectrometer (6430 QqQ) with ESI ion source and equipped with binary pump, autosampler and thermostated column compartment. The reverse-phase separations were performed on Agilent Zorbax Eclipse Plus C18 column $(100 \times 2.1 \mathrm{~mm}, 1.8 \mu \mathrm{m}$ particle size) at $35^{\circ} \mathrm{C}$. The solvent composition and the gradient program applied for the analysis was followed as described by Elez Garofulić et al. (2018) [25]. The injection volume of sample was $2.5 \mu \mathrm{L}$ and the flow rate was set at $0.3 \mathrm{~mL} \mathrm{~min}^{-1}$. Electrospray ionization (ESI) was done in both negative and positive ion modes $(\mathrm{m} / z 100$ to 1000$)$ for peak identification and the data were collected in the multiple reactions monitoring mode (MRM). The ionization source parameters for analysis were set as follows: positive/negative capillary voltage, $4000 / 3500 \mathrm{~V}$, drying gas temperature of $300{ }^{\circ} \mathrm{C}$ with a flow rate of $11 \mathrm{~L} \mathrm{~h}^{-1}$ and nebulizer pressure 40 psi. High purity nitrogen gas (Messer Ltd., Šibice, Croatia) has been used as inducing cone and collision gas. Instrument control, qualitative and quantitative data collection were performed using Agilent Mass Hunter workstation software. Identification of the phenolic compounds was carried out by comparing mass spectra and fragmentation patterns of the authentic standards. Identification of the compounds lacking authentic standards was performed on the basis of previously reported mass spectral data and mass fragmentation patterns [35-48]. All standards were qualified and quantified in MRM mode, using the optimized specific parameters: retention time, precursor ion, product ion, fragmentor voltage, collision energy and ionization mode. Quantitative determinations were carried out using external standard method and in case of lacking analytical standards quantification was carried out using calibration curves of standards from corresponding phenolic group. The limit of detection (LOD) and limit of quantification (LOQ) for the phenolic compounds were expressed by 3 - and 10-fold of the ratio of the signal-to-noise $(\mathrm{S} / \mathrm{N})$ and reported previously in study Elez Garofulić et al. (2018) [25]. The obtained values of percentage recovery of standard compounds after spiking the sample with the known concentration of standard compounds were from $81-85.83 \%$. Obtained concentrations were expressed as $\mathrm{mg}$ per $100 \mathrm{~g}$ of dried matter $(\mathrm{mg} / 100 \mathrm{~g} \mathrm{dm})(n=2)$.

\subsection{Determination of Antioxidant Capacity by ORAC Method}

The ORAC assay was conducted on a 96-well microplate using a fluorescence plate reader (Clariostar. BMG LABTECH, Offenburg, Germany) according to the method by Elez Garofulić et al. (2020) [25]. The reaction consisted of $25 \mu \mathrm{L}$ of diluted extracts and $150 \mu \mathrm{L}$ of fluorescein $(75 \mathrm{nM})$ which was used as a target for free radical attack. The reaction mixtures were incubated for $30 \mathrm{~min}$ at $37^{\circ} \mathrm{C}$ and the reaction was initiated by the addition of $25 \mu \mathrm{L}$ AAPH $(240 \mathrm{mM})$ and the fluorescence was $(\lambda$ excitation $485 \mathrm{~nm}$ i $\lambda$ emission $538 \mathrm{~nm}$ ) recorded every $90 \mathrm{sec}$ for $120 \mathrm{~min}$ at $37^{\circ} \mathrm{C}$. The blank was sodium phosphate buffer $(75 \mathrm{mM}, \mathrm{pH} 7.4)$. The Trolox $(25 \mu \mathrm{L})$ was used as the standard and results were expressed as $\mu \mathrm{mol}$ of Trolox equivalent per $\mathrm{g}$ of dried matter $(\mu \mathrm{mol} \mathrm{TE} / \mathrm{g} \mathrm{dm}, n=2)$.

\subsection{Statistical Analysis}

For statistical analysis Statistica ver. 10.0 software (Statsoft Inc., Tulsa, OK, USA) was applied. Experimental part included full factorial randomized design with two independent factors: (i) plant species-6 levels and (ii) extraction method-3 levels. Descriptive statistics was used for the basic data evaluation. Dependent variables were the contents of total flavonols, flavan-3-ols, flavones, hydroxybenzoic acids, hydroxycinnamic acids and antioxidant capacity. The results were analyzed by multivariate analysis of variance (MANOVA) and marginal mean values were compared with Tukey's HSD test. Significance level $p \leq 0.05$ was assigned for all tests. 


\section{Results and Discussion}

The assessment of the biological potential of extracts of selected plant species was performed on the basis of characterization and determination of mass fractions of phenolic compounds and antioxidant capacity. Same extraction conditions of CE and advanced extraction techniques (UAE and ASE) were used to compare their efficiency. Characterization of phenolic composition in bay (Laurus nobilis L.) leaves, sage (Salvia officinalis L.) leaves, thyme (Thymus vulgaris L.) leaves, myrtle (Myrtus communis L.) leaves and berries and sea buckthorn (Hippophae rhamnoides L.) berries was analyzed by UPLC/ESI-MS ${ }^{2}$ method.

\subsection{Characterization of Selected MAP Extracts by UPLC-ESI/MS2 Analysis}

MAP extracts comprised flavonols (FOL), flavan-3-ols (FLAOL), flavones (FON), phenolic acids [hydroxybenzoic (HBA) and hydroxycinnamic acids (HCA)], anthocyanins (ANT), lignans (LG) and its derivates (Table 1). With regard to botanical and morphological characteristics, differences in the phenolic composition of plants were observed and the identified compounds are arranged into their constituent groups and occurrence in each of the MAP extracts (Table 2).

Among the FOL, compounds (cp) 8, 10, 14 and 15 were identified by comparison with authentic standards as kaempferol-3-rutinoside, myricetin, rutin and quercetin-3glucoside. Isorhamnetin glycosides were characterized due to fragment ion at $\mathrm{m} / \mathrm{z} 317$ which corresponds to aglycone isorhamnetin. Cp 1-3 were identified by characteristic release of 162, 146 and 308 amu indicating hexosyl, rhamnosyl and rhamnosyl-( $\alpha 1 \rightarrow 6)$ glucose residue [43].

In current study, isorhamnetin-3-rutinoside and isorhamnetin-3-rhamnoside were determined only in sea buckthorn berries $(4.12-22.05 \mathrm{mg} / 100 \mathrm{~g} \mathrm{dm}$ ) which contents are in accordance with research of Pop et al. (2013) [43]. The isoramnethin-3-O-hexoside was present in analyzed extracts of sage, thyme and bay leaves and sea buckthorn berries. The highest concentration of isoramnethin-3-O-hexoside was determined in bay leaves extracts $(67.18-96.09 \mathrm{mg} / 100 \mathrm{~g} \mathrm{dm})$. Similar results were obtained in the study of Dias et al. (2014) [49] where concentration of isoramnethin-3-O-hexoside in cultivated and wild bay leaves ranged from 0.2 to $1.29 \mathrm{mg} / \mathrm{g}$ of extract.

$\mathrm{Cp} 4$ identified as aglycon kaempferol was characterized by fragment ion at $\mathrm{m} / \mathrm{z}$ 145 and losses corresponding to $2 \mathrm{CO}(-56 \mathrm{amu})$ and $2 \mathrm{C}_{2} \mathrm{H}_{2} \mathrm{O}(-84 \mathrm{amu})$ [37]. $\mathrm{Cp}$ 5-9 were identified as kaempferol glycosides characterized by specific fragment ion at $m / z$ 287. They were tentatively identified as kaemferol-3-O-hexoside, kaemferol-3-Opentoside, kaempferol-rhamnoside and kaempferol-sophoroside-rhamnoside due to losses corresponding to hexose $(-162 \mathrm{amu})$, pentose $(-132 \mathrm{amu})$, rhamnose $(-146 \mathrm{amu})$ and sophorose $(-178 \mathrm{amu})[40,50]$.

Cp 15-18 were identified as quercetin glycosides due to characteristic fragment ion at $m / z$ 303. They were assigned as quercetin-3-glucoside, quercetin-3-rhamnoside, quercetin-3-sophoroside-7-rhamnoside and quercetine-3-pentoside due to losses corresponding to hexose $(-162 \mathrm{amu})$, rhamnose $(-146 \mathrm{amu})$, sophorose $(-178 \mathrm{amu})$ and pentose $(-132 \mathrm{amu})$ [45]. 


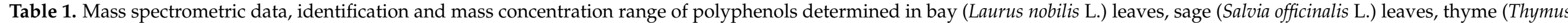
vulgaris L.) leaves, myrtle (Myrtus communis L.) leaves and berries and sea buckthorn (Hippophae rhamnoides L.) berries.

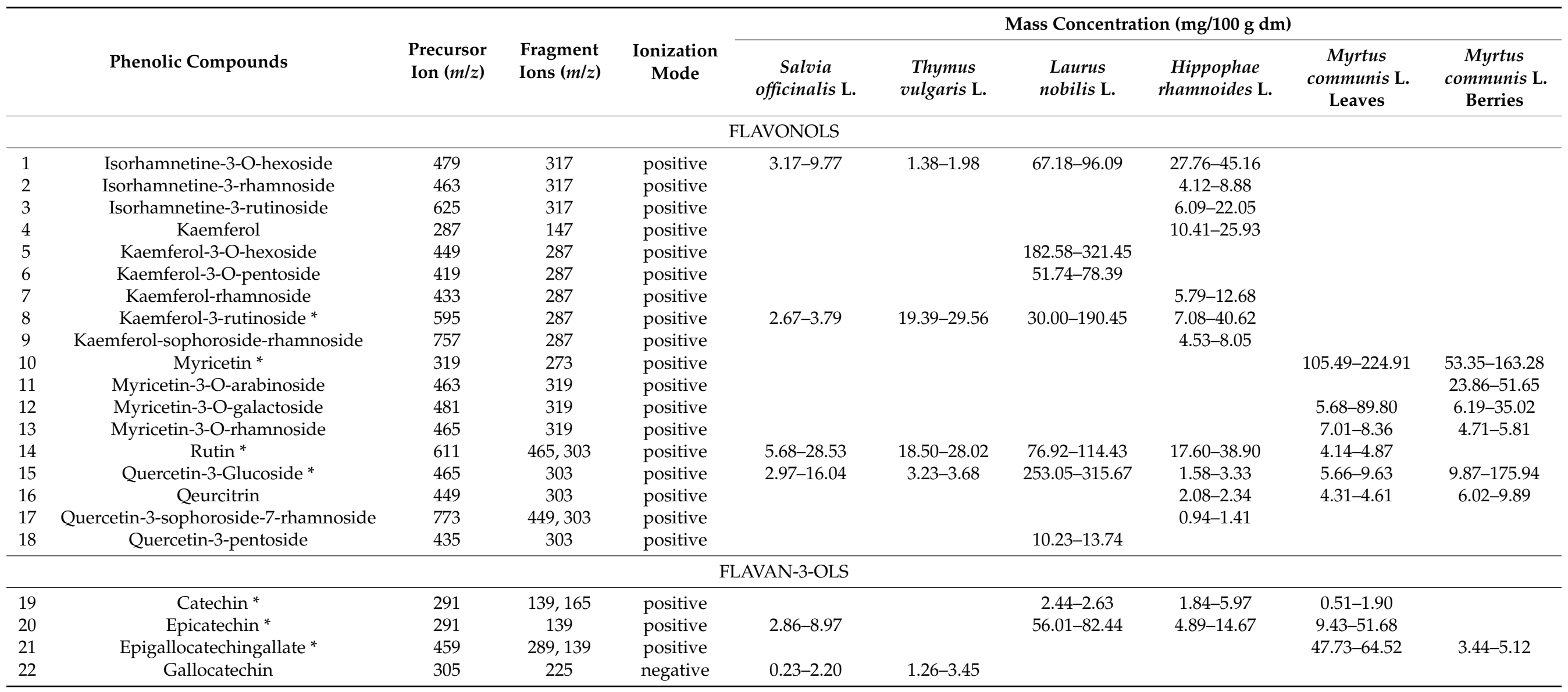


Table 1. Cont

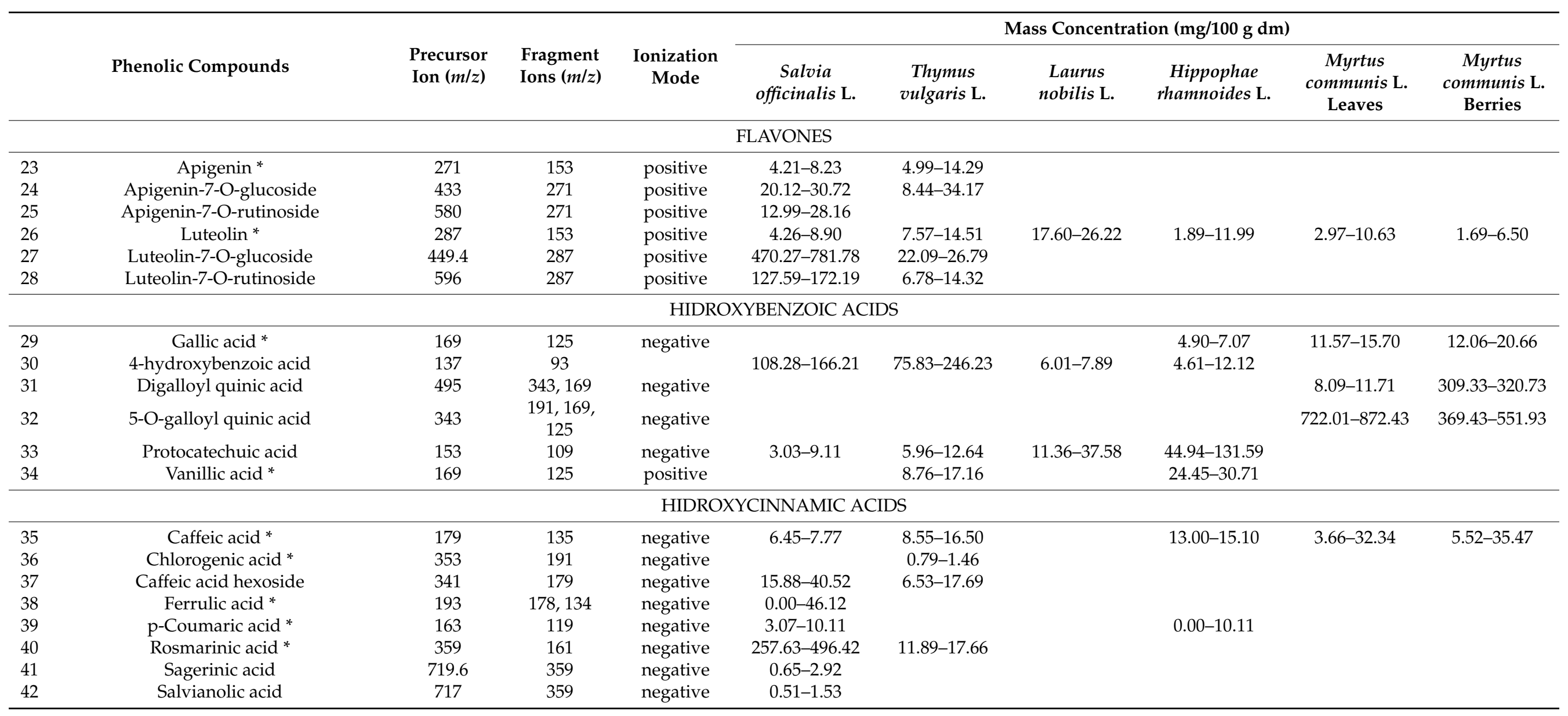


Table 1. Cont.

\begin{tabular}{|c|c|c|c|c|c|c|c|c|c|c|}
\hline & \multirow[b]{2}{*}{ Phenolic Compounds } & \multirow[b]{2}{*}{$\begin{array}{c}\text { Precursor } \\
\text { Ion }(\mathrm{m} / \mathrm{z})\end{array}$} & \multirow[b]{2}{*}{$\begin{array}{l}\text { Fragment } \\
\text { Ions }(m / z)\end{array}$} & \multirow[b]{2}{*}{$\begin{array}{l}\text { Ionization } \\
\text { Mode }\end{array}$} & \multicolumn{6}{|c|}{ Mass Concentration (mg/100 g dm) } \\
\hline & & & & & $\begin{array}{c}\text { Salvia } \\
\text { officinalis L. }\end{array}$ & $\begin{array}{c}\text { Thymus } \\
\text { vulgaris L. }\end{array}$ & $\begin{array}{c}\text { Laurus } \\
\text { nobilis L. }\end{array}$ & $\begin{array}{c}\text { Hippophae } \\
\text { rhamnoides L. }\end{array}$ & $\begin{array}{c}\text { Myrtus } \\
\text { communis L. } \\
\text { Leaves }\end{array}$ & $\begin{array}{c}\text { Myrtus } \\
\text { communis L. } \\
\text { Berries }\end{array}$ \\
\hline & \multicolumn{10}{|c|}{ ANTHOCYANINS } \\
\hline 43 & Cyanidin-3-glucoside & 449 & 287 & positive & & & & & & $22.40-43.91$ \\
\hline 44 & Delfinidin-3-O-glucoside & 465 & 303 & positive & & & & & & $6.04-110.26$ \\
\hline 45 & Delfinidin-pentoside & 435 & 303 & positive & & & & & & $2.96-96.79$ \\
\hline 46 & Malvidin-3-O-glucoside & 493 & 331 & positive & & & & & & $144.54-287.62$ \\
\hline 47 & Petunidin-3-arabinoside & 449 & 317 & positive & & & & & & $18.20-53.38$ \\
\hline 48 & Petunidin-3-glucoside & 479 & 317 & positive & & & & & & $37.46-174.09$ \\
\hline 49 & Petunidin-pentoside & 449 & 317 & positive & & & & & & $17.62-53.75$ \\
\hline \multirow[t]{2}{*}{50} & Peonidin-3-O-glucoside & 463 & 303 & positive & & & & & & $16.27-30.07$ \\
\hline & & & & & LIGNANS & & & & & \\
\hline 51 & Carnosic acid & 331 & 287 & negative & $155.75-292.01$ & $6.26-16.45$ & & & & \\
\hline 52 & Carnosol & 329 & 285 & negative & & $2.63-5.68$ & & & & \\
\hline 53 & Epirosmanol & 345 & 283 & negative & $3.00-9.57$ & $0.33-0.65$ & & & & \\
\hline 56 & Salvigenin & 329 & 296 & positive & $0.41-0.77$ & & & & & \\
\hline
\end{tabular}

* Identification confirmed using authentic standards. 


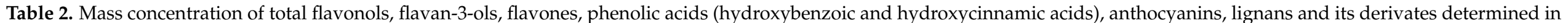

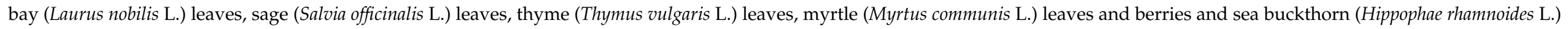
berries extracts obtained by different extraction techniques.

\begin{tabular}{|c|c|c|c|c|c|c|c|c|c|}
\hline \multirow{2}{*}{ Plant Species } & \multirow{2}{*}{ Method } & \multicolumn{8}{|c|}{ Mass Concentration (mg/100 g dm) } \\
\hline & & FOL $^{1}$ & FLAOL $^{2}$ & FON $^{3}$ & HBA $^{4}$ & HCA $^{5}$ & $\mathrm{LG}^{6}$ & ANT $^{7}$ & ORAC $^{8}$ \\
\hline \multirow{3}{*}{ Sage leaves } & $\mathrm{CE}$ & $36.34 \pm 0.49$ & $3.10 \pm 0.17$ & $752.99 \pm 7.09$ & $135.7 \pm 1.09$ & $434.89 \pm 5.34$ & $375.62 \pm 0.01$ & nd & $729.32 \pm 1.48$ \\
\hline & UAE & $14.49 \pm 0.41$ & $9.43 \pm 0.06$ & $639.44 \pm 3.07$ & $112.31 \pm 0.99$ & $318.11 \pm 2.04$ & $211.49 \pm 1.56$ & nd & $899.04 \pm 2.43$ \\
\hline & ASE & $58.14 \pm 0.04$ & $5.06 \pm 0.33$ & $1027.56 \pm 0.60$ & $175.31 \pm 1.68$ & $557.95 \pm 5.85$ & $309.61 \pm 1.54$ & nd & $949.31 \pm 0.55$ \\
\hline \multirow{3}{*}{ Thyme leaves } & $\mathrm{CE}$ & $53.11 \pm 1.64$ & $3.45 \pm 0.12$ & $55.29 \pm 1.29$ & $97.37 \pm 0.86$ & $34.13 \pm 1.52$ & $36.98 \pm 1.21$ & nd & $377.36 \pm 2.48$ \\
\hline & UAE & $49.88 \pm 0.89$ & $1.26 \pm 0.01$ & $57.77 \pm 2.25$ & $179.3 \pm 0.68$ & $46.33 \pm 0.82$ & $19.07 \pm 0.29$ & nd & $233.76 \pm 3.13$ \\
\hline & ASE & $55.66 \pm 2.43$ & $2.10 \pm 0.01$ & $104.08 \pm 5.40$ & $269.35 \pm 4.74$ & $39.59 \pm 1.60$ & $19.91 \pm 1.90$ & nd & $368.34 \pm 3.14$ \\
\hline \multirow{3}{*}{ Myrtle leaves } & CE & $244.79 \pm 3.01$ & $114.57 \pm 1.27$ & $2.97 \pm 0.50$ & $898.88 \pm 0.70$ & $32.34 \pm 1.07$ & nd & nd & $974.85 \pm 3.79$ \\
\hline & UAE & $134.16 \pm 2.47$ & $74.46 \pm 2.32$ & $5.12 \pm 0.05$ & $753.82 \pm 3.02$ & $4.45 \pm 0.40$ & nd & nd & $626.72 \pm 0.76$ \\
\hline & ASE & $259.91 \pm 2.63$ & $65.93 \pm 0.39$ & $10.63 \pm 0.46$ & $746.13 \pm 3.45$ & $3.66 \pm 2.82$ & nd & nd & $569.89 \pm 0.60$ \\
\hline \multirow{3}{*}{ Myrtle berries } & CE & $212.58 \pm 2.65$ & $3.44 \pm 0.03$ & $6.5 \pm 0.01$ & $567.71 \pm 2.02$ & $5.81 \pm 0.03$ & nd & $442.13 \pm 7.07$ & $412.68 \pm 2.40$ \\
\hline & UAE & $302.83 \pm 0.77$ & $5.12 \pm 0.15$ & $1.69 \pm 0.09$ & $874.44 \pm 3.09$ & $5.52 \pm 0.06$ & nd & $947.13 \pm 90.14$ & $504.98 \pm 3.53$ \\
\hline & ASE & $249.22 \pm 00.69$ & $4.15 \pm 0.05$ & $3.20 \pm 0.08$ & $892,97 \pm 0,19$ & $35.47 \pm 1.01$ & nd & $297.38 \pm 0.75$ & $636.97 \pm 1.50$ \\
\hline \multirow[t]{2}{*}{ Bay leaves } & UAE & $722.71 \pm 5.31$ & $58.46 \pm 1.15$ & $23.15 \pm 0.92$ & $17.36 \pm 0.71$ & nd & nd & nd & $410.19 \pm 1.70$ \\
\hline & ASE & $1130.22 \pm 0.85$ & $64.96 \pm 0.87$ & $26.22 \pm 0.92$ & $45.47 \pm 0.27$ & nd & nd & nd & $615.86 \pm 2.03$ \\
\hline \multirow{3}{*}{ Sea buckthorn berries } & $\mathrm{CE}$ & $88.31 \pm 3.65$ & $6.72 \pm 0.16$ & $1.89 \pm 0.63$ & $179.31 \pm 3.55$ & $15.10 \pm 1.31$ & nd & nd & $69.77 \pm 0.72$ \\
\hline & UAE & $163.24 \pm 4.37$ & $20.64 \pm 0.26$ & $3.47 \pm 0.04$ & $145.95 \pm 2.33$ & $24.11 \pm 0.95$ & nd & nd & $72.21 \pm 1.24$ \\
\hline & ASE & $188.83 \pm 4.64$ & $11.77 \pm 0.10$ & $11.99 \pm 0.75$ & $79.38 \pm 2.82$ & $22.37 \pm 0.56$ & nd & nd & $70.24 \pm 1.24$ \\
\hline
\end{tabular}

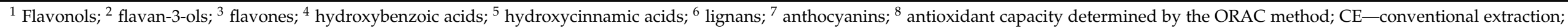

UAE-ultrasound-assisted extraction; ASE-accelerated solvent extraction. Results are expressed as mean \pm standard deviation. 
The most abundant quercetin and kaempferol glycosides were quercetin-3-glucoside (253.05-315.67 mg/100 g dm) and kaemferol-3-O-hexoside (182.58-321.45 mg/100 g dm) determined in bay leaves. Dias et al. (2014) [49] also reported similar concentrations of quercetin-3-glucoside $(0.76-4.32 \mathrm{mg} / \mathrm{g})$ and kaemferol-3-O-hexoside $(0.76-4.32 \mathrm{mg} / \mathrm{g})$ in bay leaves. The high content of kaempferol-3-rutinoside (30-190.45 mg/100 g dm) and rutin $(76.92-114.43 \mathrm{mg} / 100 \mathrm{~g} \mathrm{dm}$ ) was also determined in extracts of bay leaves. According to Kaurinovic and Vastag (2019) [12], major bioactive compounds in bay leaves were kaempferol-3-O-glucoside, quercetin and rutin. The high content of quercetin-3-glucoside (9.87-175.94 mg/100 g dm) was also determined in analyzed myrtle berry extracts. In study of Barboni et al. (2010) [51] generally higher concentrations of quercetin-3-glucoside ( 79.9 to $1130 \mathrm{mg} / 100 \mathrm{~g} \mathrm{dm}$ ) in myrtle berries were determined when compared to the results in current study. These differences could be attributed to variation of locality and harvesting year, however applied defatting pre-treatment, by which plant lipids and lipophilic compounds have been removed could also result in loss of phenolics.

Myricetin and glycoside derivates were the major flavonoid constituents determined in myrtle leaves and berries. Cp 11-13 were tentatively assigned as myricetin derivates due to characteristic fragment ion at $m / z 319$.

Cp $11(m / z 451)$ was tentatively proposed as myricetin-arabinoside based on its fragmentation pattern, which yielded fragment ions at $m / z 319$ after a loss of the arabinosyl moiety ( $-132 \mathrm{amu}$ ) [44]. Cp 12 and 13 characterized by a fragment ion at $m / z 319$ and loss of galactose $(-162 \mathrm{amu})$ and rhamnose $(-146 \mathrm{amu})$ were assigned as myricetin-3-galactoside and myricetin-3-rhamnoside [36,46]. Myricetin was the most abundant FOL in myrtle leaves and berries (105.49-224.91 mg/100 g dm and 53.35-163.28 mg/100 g dm). The most abundant myricetin derivates in myrtle leaves and berries were myricetin-3-O-galactoside (5.68-89.80 mg/100 g dm) and myricetin-3-O-arabinoside (23.86-51.65 mg/100 g dm), respectively. These results are in accordance with those reported by Barboni et al. (2010) [51] where the major compounds among FOL and its glycosides in myrtle berries were myricetin3-galactoside (106.00-1435.90 mg/100 g dm) and myricetin (207.80-1053.60 mg/100 g dm). Pereira et al. (2016) [52] also reported that myricetin-3-O-galactoside, myricetin-3-Orhamnoside and quercetin-3-O-rhamnoside were the main flavonoids identified in the extracts of myrtle leaves.

According to results in current study, the highest content of total FOL was determined in bay leaves (722.71-1130.22 $\mathrm{mg} / 100 \mathrm{~g} \mathrm{dm}$ ) followed by myrtle berries (212.58-302.83 mg/100 g dm) and leaves (134.16-259.91 mg/100 g dm), sea buckthorn berries (88.31-188.83 mg/100 $\mathrm{g} \mathrm{dm})$, and leaves of thyme $(49.88-55.66 \mathrm{mg} / 100 \mathrm{~g} \mathrm{dm})$ and sage (36.444-58.136 mg/100 g dm).

Belonging to the class of FLAOL, cp 19, 20 and 21 were identified by comparison with authentic standards and were assigned as catechin, epicatechin and epigallocatechin gallate. Cp $22(m / z 305)$ was assigned as gallocatechin on the basis of fragmentation pattern with the fragment ion $m / z 225$ [39].

Among identified FLAOL the most abundant compounds were epicatechin (56.01-82.44 mg/100 $\mathrm{g} \mathrm{dm}$ ) determined in bay leaves and epigallocatechin gallate (47.73-64.52 mg/100 g dm) determined in myrtle leaves, respectively. Dias et al. [49] reported that FLAOL were the major phenolic compounds present in bay leaves with (-)-epicatechin (12.35-23.08 mg/g) being the most abundant one. Romani et al. (1999) [36] reported higher content of epigallocatechin in myrtle leaves $(2710 \mu \mathrm{g} / \mathrm{g} \mathrm{dm})$ in comparison with results in current study.

Furthermore, content of total FLAOL in analyzed plant extracts decreased in the following order: myrtle leaves $(65.93-114.57 \mathrm{mg} / 100 \mathrm{~g} \mathrm{dm})$, bay leaves $(58.46-85.02 \mathrm{mg} / 100 \mathrm{~g} \mathrm{dm})$, sea buckthorn berries $(6.72-20.64 \mathrm{mg} / 100 \mathrm{~g} \mathrm{dm})$, myrtle berries $(3.44-5.12 \mathrm{mg} / 100 \mathrm{~g} \mathrm{dm}$ ) and thyme leaves $(1.26-3.45 \mathrm{mg} / 100 \mathrm{~g} \mathrm{dm})$.

Among FON, cp 23 and 26 were identified as apigenin and luteolin by comparison with authentic standards. Cp 24-25 and 27-28 were characterized by fragment ion at $m / z 271$ corresponding to apigenin and $m / z 287$ corresponding to luteolin. They were 
assigned as apigenin-7-O-glucoside, apigenin-7-O-rutinoside, luteolin-7-O-glucoside and luteolin-7-O-rutinoside due to loses of glucoside $(-162 \mathrm{amu})$ and rutinoside $(-309 \mathrm{amu})$ which is in accordance with previously reported data [39].

FON were mainly distributed in sage and thyme, what corresponds to literature data $[10,53]$. When compared to apigenin, luteolin glycosides appeared in a higher concentration in sage extracts, which was also previously reported by Dent et al. (2015) [54]. Other studies reported apigenin-7-glucoside and luteolin-7-glucoside as the main FON in Salvia sp. [55-57].

The most abundant FON determined in analyzed sage extracts were luteolin-7-glucoside (470.27-781.78 mg/100 g dm) and luteolin-7-O-rutinoside (127.59-172.19 mg/100 g dm). Considerably lower concentration of luteolin-7-O-glucoside (22.09 to $26.79 \mathrm{mg} / 100 \mathrm{~g} \mathrm{dm}$ ) was determined in thyme. The concentration of apigenin-7-O-glucoside was determined in thyme in range from 8.44 to $34.17 \mathrm{mg} / 100 \mathrm{~g} \mathrm{dm}$. Kulišić et al. (2006) [58] and Dapkevicius et al. (2002) [59] also reported the presence of luteolin-7-O-glucoside and apigenin-7-Oglucoside in thyme infusions and leaves. The study of Sonmezdag et al. (2015) [60] showed that luteolin-7-O-glucoside was the most abundant compound determined in wild thyme. Our results are in accordance with the study of Martins et al. (2015) [53] which found luteolin-7-O-glucoside to be the most abundant FON in sage extracts.

Sage extracts sowed 10- to 13-fold higher content of total FON (639.44-1027.56 mg/100 g dm) when compared to thyme (55.29-104.08 $\mathrm{mg} / 100 \mathrm{~g} \mathrm{dm}$ ). In other MAP total FON ranged from $1.89 \mathrm{mg} / 100 \mathrm{~g} \mathrm{dm}$ (sea buckthorn) to $23.15 \mathrm{mg} / 100 \mathrm{~g} \mathrm{dm}$ (bay).

In addition to flavonoids, analyzed plant extracts contained a large amount of phenolic acids (HBA and HCA) and LG.

Cp 29, 34-36 and 38-40 were identified by comparison with authentic standards as gallic, vanillic, caffeic, chlorogenic, ferulic, p-coumaric and rosmarinic acid. The ESI-MS signals at $m / z 153$ and 137 were identified as protocatechuic and 4-hydroxybenzoic acids on the basis of fragmentation pattern with the fragment ions $m / z 109$ and 93 which correspond to the loss of $\mathrm{CO}_{2}$ from their precursor ions, respectively [39].

Cp 31 and 32 determined in both myrtle leaves and berries were assigned as gallic acid derivates tentatively identified as digalloylquinic acid and 5-O-galloylquinic acid due to precursor ions at $m / z 495$ and 343 and fragment ions at $m / z 343,191,169$ and $125[41,44,61]$.

The most abundant HBA was 5-O-galloylquinic acid determined in myrtle leaves (722.01-872.43 mg/100 g dm) and berries (369.43-551.93 mg/100 g dm). A considerably lower content of gallic acid and galloyl derivates found in myrtle leaves extracts was reported by Taamalli et al. (2014) [44].

Zadernowskia et al. (2005) [62], Hossain et al. (2010) [39], Vallverdú-Queralt et al., (2014) [63] and Kaurinovic and Vastag (2019) [12] reported the presence of 4-hydroxybenzoic (сp 30) and protocatechuic acid (cp 33) in Lamiaceae, Lauraceae and Elaeagnaceae sp.

Cp $37(m / z$ 341) was assigned as caffeic acid hexoside on the basis of fragmentation pattern with the fragment ion at $m / z 179$ which correspond to caffeic acid (Hossain et al., 2010) [39].

Cp 41 and 42 determined in sage with $\mathrm{MS}^{2}$ fragment at $m / z 359$ corresponding to rosmarinic acid were identified as salvianolic and sagerinic acid. The fragmentation pattern was previously reported by Sharma et al. (2020) [48]. The presence of caffeic and rosmarinic acid and its derivates was previously reported by Lu and Foo (2000) [57] and Hossain et al. (2010) [39]. The major phenolic acids in Salvia sp. are caffeic acid derivates (Kamatou, 2010) [64]. Among the identified HCA, rosmarinic acid was detected in the highest amount in sage extracts (257.63-496.42 mg/100 g dm). These results are in accordance with the study of Martins et al. (2015) [53] where rosmarinic acid was the most abundant phenolic acid in extracts of sage.

LG were determined only in analyzed extracts of Lamiaceae sp. Cp 51-56 were identified by comparison with literature data $[39,48]$ as carnosic acid (MS $m / z$ fragment 287), carnosol (MS ${ }^{2} m / z$ fragment 285), epirosmanol (MS ${ }^{2} m / z$ fragment 283), methyl carnosate (MS $2 \mathrm{~m} / z$ fragment 301), medioresinol (MS $2 \mathrm{~m} / z$ fragment 207) and salvigenin 
(MS $2 \mathrm{~m} / z$ fragment 296). The most represented LG was carnosic acid detected in sage (155.75-292 mg/100 g dm) and thyme extracts $(6.26-16.45 \mathrm{mg} / 100 \mathrm{~g} \mathrm{dm})$. These results are in accordance with the study of Tounekti et al. (2010) [65] where the concentration of carnosic acid in leaves of Dalmatian sage was $2.12 \mathrm{mg} / \mathrm{g} \mathrm{dm}$. Content of carnosic acid determined in thyme extracts was also in accordance with the results of Roby et al. (2013) [10]. In comparison with carnosic acid, medioresinol (28.43-73.09 mg/100 g dm) and methyl carnosate $(19.67-66.15 \mathrm{mg} / 100 \mathrm{~g} \mathrm{dm})$ were determined in considerably lower concentration in sage then in thyme (3.27-10.29 mg/100 g dm).

Only myrtle berries were characterized by the presence of ANT, namely cyanidine-3glucoside, delphinidine-3-O-glucoside, delphinidin-pentoside, malvidine-3-O-glucoside, petunidine-3-arabinoside petunidine-3-glucoside, petunidin-pentoside and peonidine-3-Oglucoside. Cp 44-45 and 47-49 were identified as delphinidin and petunidin glycosides due to characteristic fragment ions at $m / z 303$ and 317. Cp 43, 46 and 50 were identified as cyanidine-3-glucoside $(m / z 449)$, malvidine-3-O-glucoside $(m / z 493)$ and peonidine-3-Oglucoside $(m / z 463)$. The fragmentation pattern of anthocyanins is consistent with previously reported data [38,47]. Maldini et al. (2016) [47], Sarais et al. (2016) [66], Scorrano et al. (2017) [67] and Siracusa et al. (2019) [68] reported that anthocyanins in myrtle berries are mainly represented by delphinidine-3-O-glucoside, petunidin-3-O-glucoside, malvidine-3O-glucoside, and peonidine-3-glucoside, followed by cyanidine-3-glucoside, delphinidinpentoside and petunidin-pentoside. Content of total ANT in analyzed extracts of myrtle berries was in range from 297.38 to $947.13 \mathrm{mg} / 100 \mathrm{~g} \mathrm{dm}$. These results are considerably higher than those reported by Fadda et al. (2016) [69]. In general, glucoside derivates of ANT such as malvidine-3-glucoside (144.54-287.62 mg/100 g dm), petunidin-3-glucoside (37.46-174.09 mg/100 g dm) and delphnidin-3-glucoside (6.04-110.26 mg/100 g dm) were the most abundant compounds in analyzed extracts of myrtle berries.

Current study showed great diversity and complexity of natural mixtures of phenolic compounds in extracts of morphologically and botanically different plants. The total content of phenolic groups determined in selected MAP extracts of leaves and fruits obtained with different extraction techniques are shown in Table 2. Results showed that dominant group of phenolic compounds were FON in sage, FOL in bay and sea buckthorn, and HBA in thyme and myrtle.

When observing the influence of plant species on the content of phenolics, the difference in total content of each phenolic group was statistically significant (Table 3). In general, the highest content of total FON (806.66 mg/100 g dm), HCA (436.98 mg/100 g dm) and LG $(298.91 \mathrm{mg} / 100 \mathrm{~g} \mathrm{dm})$ was determined in extracts of sage leaves. Total FLAOL $(84.99 \mathrm{mg} / 100 \mathrm{~g} \mathrm{dm})$ and HBA $(799.61 \mathrm{mg} / 100 \mathrm{~g} \mathrm{dm})$ were the highest in extracts of myrtle leaves, while the highest content of total FOL $(866.31 \mathrm{mg} / 100 \mathrm{~g} \mathrm{dm})$ characterized extracts of bay leaves.

The content of phenolic compounds in selected MAPs also varied upon extraction method used (Table 2). The highest contents of total FOL and FON in sage, thyme, bay, myrtle and sea buckthorn extracts were obtained when ASE was applied, except for FON in myrtle berries which were the highest in extracts obtained by CE. ASE also contributed to the highest content of total HBA in extracts of leaves of sage, thyme and bay, and myrtle berries. Moreover, the highest yields of total HCA in sage leaves and myrtle berries extracts were also achieved when ASE was used. This good performance of ASE derives from the fact that under high pressure solvent remains in liquid state even at temperatures higher than their boiling point which improves the extraction efficiency by "pushing" the solvent into pores and allowing better penetration into the matrix [70]. Rapid solvent penetration prevents the degradation of phenolic compounds despite that ASE is carried out under high temperature and pressure [71]. Contrary, ASE was the least suitable method for the extraction of total HBA in sea buckthorn berries and total FLAOL, HBA and HCA in myrtle leaves. 
Table 3. The influence of applied extraction method and plant species on the mass concentration of polyphenols and antioxidant capacity of obtained extracts.

\begin{tabular}{|c|c|c|c|c|c|c|c|c|}
\hline \multirow{2}{*}{ Source of Variation } & \multicolumn{8}{|c|}{ Mass Concentration (mg/100 g dm) } \\
\hline & FOL $^{1}$ & FLAOL $^{2}$ & FON $^{3}$ & HBA $^{4}$ & $\mathrm{HCA}^{5}$ & $\mathrm{LG}^{6}$ & ANT $^{7}$ & ORAC $^{8}$ \\
\hline Method & $p<0.05$ & $p<0.05$ & $p<0.05$ & $p<0.05$ & $p<0.05$ & $p<0.05$ & $p<0.05$ & $p<0.05$ \\
\hline CE & $230.19 \pm 1.18 \mathrm{a}$ & $36.05 \pm 0.30 c$ & $139.54 \pm 0.96 b$ & $310.96 \pm 0.92 \mathrm{a}$ & $87.04 \pm 0.89 b$ & $206.3 \pm 0.91 c$ & $442.13 \pm 52.21 \mathrm{a}$ & $479.13 \pm 0.87 b$ \\
\hline UAE & $231.22 \pm 1.18 \mathrm{a}$ & $28.23 \pm 0.30 \mathrm{~b}$ & $121.77 \pm 0.96 \mathrm{a}$ & $336.10 \pm 0.92 b$ & $66.42 \pm 0.89 \mathrm{a}$ & $115.28 \pm 0.91 \mathrm{a}$ & $947.13 \pm 52.21 b$ & $457.82 \pm 0.87 \mathrm{a}$ \\
\hline ASE & $323.66 \pm 1.18 b$ & $25.66 \pm 0.30 \mathrm{a}$ & $197.28 \pm 0.96 c$ & $384.76 \pm 0.92 \mathrm{c}$ & $109.84 \pm 0.89 c$ & $164.76 \pm 0.91 b$ & $297.38 \pm 52.21 \mathrm{a}$ & $535.11 \pm 0.87 c$ \\
\hline Plant species & $p<0.05$ & $p<0.05$ & $p<0.05$ & $p<0.05$ & $p<0.05$ & $p<0.05$ & $p<0.05$ & $p<0.05$ \\
\hline Sage leaves & $36.32 \pm 1.67 \mathrm{a}$ & $5.86 \pm 0.43 \mathrm{a}$ & $806.66 \pm 1.35 \mathrm{~d}$ & $141.11 \pm 1.29 c$ & $436.98 \pm 1.26 \mathrm{~d}$ & $298.91 \pm 0.74 b$ & nd & $85.23 \pm 1.22 \mathrm{f}$ \\
\hline Myrtle leaves & $212.96 \pm 1.67 \mathrm{~d}$ & $84.99 \pm 0.43 \mathrm{e}$ & $6.24 \pm 1.35 \mathrm{a}$ & $799.61 \pm 1.29 \mathrm{f}$ & $13.48 \pm 1.26 \mathrm{a}$ & nd & nd & $723.82 \pm 1.22 \mathrm{e}$ \\
\hline Myrtle berries & $254.88 \pm 1.67 \mathrm{e}$ & $4.24 \pm 0.43 \mathrm{a}$ & $3.8 \pm 1.35 \mathrm{a}$ & $778.38 \pm 1.29 \mathrm{e}$ & $15.6 \pm 1.26 \mathrm{ab}$ & nd & $562.21 \pm 52.21 \mathrm{a}$ & $518.21 \pm 1.22 \mathrm{~d}$ \\
\hline Bay leaves & $866.31 \pm 1.67 \mathrm{f}$ & $69.48 \pm 0.43 \mathrm{~d}$ & $22.32 \pm 1.35 b$ & $27.65 \pm 1.29 \mathrm{a}$ & nd & nd & nd & $445.60 \pm 1.22 c$ \\
\hline $\begin{array}{l}\text { Sea buckthorn } \\
\text { berries }\end{array}$ & $146.79 \pm 1.67 \mathrm{c}$ & $13.04 \pm 0.43 c$ & $5.79 \pm 1.35 \mathrm{a}$ & $134.88 \pm 1.29 b$ & $20.53 \pm 1.26 b$ & nd & nd & $70.74 \pm 1.22 \mathrm{a}$ \\
\hline
\end{tabular}

${ }^{1}$ Flavonols; ${ }^{2}$ flavan-3-ols; ${ }^{3}$ flavones, ${ }^{4}$ hydroxybenzoic acids; ${ }^{5}$ hydroxycinnamic acids; ${ }^{6}$ lignans; ${ }^{7}$ anthocyanins; ${ }^{8}$ antioxidant capacity determined by the ORAC method;

$\mathrm{UAE}-$ ultrasound-assisted extraction; ASE—accelerated solvent extraction. Results are expressed as mean $\pm \mathrm{SE}$. Values with different letters are statistically different at $p \leq 0.05$. 
The UAE was more efficient in comparison with ASE and CE in extracting FLAOL from sea buckthorn, HCA from thyme and sea buckthorn, and ANT from myrtle berries. On the other hand, CE contributed to the higher content of FLAOL, HBA and HCA in extracts of myrtle leaves, LG in sage and thyme, FLAOL in bay and HBA in sea buckthorn. UAE is useful method for thermolabile compounds since active components rapidly diffuse by sonication from plant tissue to solvent, thus shortening the extraction time [72]. The choice of an appropriate extraction method considerably depends on the nature of the plant matrix [71]. For example, literature data showed that ASE was more suitable extraction method for mulberry, UAE for myrtle berries and CE for sweet purple potatoes phenolics [73-75].

According to statistical analysis, extraction method significantly affected total content of FLAOL, FON, HBA, HCA and LG (Table 3). Significantly higher concentrations of total FOL (323.66 mg/100 g dm), FON (197.28 mg/100 g dm), HCA (109.84 mg/100 g dm) and HBA $(384.76 \mathrm{mg} / 100 \mathrm{~g} \mathrm{dm}$ ) were obtained by ASE, while significantly higher amounts of total ANT $(947.13 \mathrm{mg} / 100 \mathrm{~g} \mathrm{dm})$ and FLAOL $(36.05 \mathrm{mg} / 100 \mathrm{~g} \mathrm{dm})$ were achieved by UAE and $\mathrm{CE}$, respectively.

Various structures of phenolics are present in different MAP and they have different physical and chemical characteristics (molecular structure, polarity, concentration, number of aromatic rings and hydroxyl groups) as well as diverse interactions with other compounds (proteins or carbohydrates). This significantly affects the extraction processes [14]. Therefore, it is difficult to use single extraction method for all classes of MAP phenolic compounds. Still, advanced extraction techniques are always preferred due to great disadvantages of conventional extraction procedures. Analyzed extracts of selected MAP showed to be a good source of different phenolics and obtained results indicated suitable extraction methods for target phenolic compounds characteristic for certain plant species.

\subsection{Antioxidant Capacity (AC)}

In extracts of selected MAP obtained by different extraction techniques (CE, UAE and ASE) antioxidant capacity (AC) was determined by ORAC assay (Table 2). When comparing all plant extracts, the highest $\mathrm{AC}$ was determined in extracts of myrtle leaves (569.89-974.85 $\mu \mathrm{mol} \mathrm{TE} / \mathrm{g} \mathrm{dm}$ ), followed by sage leaves $(729.32-949.31 \mu \mathrm{mol} \mathrm{TE} / \mathrm{g} \mathrm{dm})$, myrtle berries (412.68-636.97 $\mu \mathrm{mol} \mathrm{TE} / \mathrm{g} \mathrm{dm})$, bay leaves (310.77-615.86 $\mu \mathrm{mol} \mathrm{TE} / \mathrm{g} \mathrm{dm})$, thyme leaves (233.76-377.36 $\mu \mathrm{mol} \mathrm{TE} / \mathrm{g} \mathrm{dm})$ and sea buckthorn berries $(69.77-72.21 \mu \mathrm{mol} \mathrm{TE} / \mathrm{g} \mathrm{dm})$. Regarding extraction methods, sage, bay, sea buckthorn and myrtle berries extracts obtained by ASE and extracts of myrtle and thyme leaves obtained by CE showed the highest ORAC values. ORAC values determined in plant extracts of myrtle and sage were in accordance with previously reported data $[76,77]$. Moreover, literature data suggested that myrtle extracts have a potent AC mainly due to presence of HBA, FOL and galloyl derivatives [61,78]. In study of Kratchanova et al. (2010) [79], higher AC was determined in extracts of thyme (1434-1637 $\mu \mathrm{mol} \mathrm{TE} / \mathrm{g})$ and bay $(170-837 \mu \mathrm{mol} \mathrm{TE} / \mathrm{g})$ when compared to AC values in current study. Higher AC in sea buckthorn (18.41-34.68 mmol TE/100 g) was also determined in study of Tkacz et al. (2019) [80].

Based on statistical analysis, significant differences in ORAC values between analyzed plant extracts were observed (Table 3). Sage extract showed the highest ORAC level $(859.23 \mu \mathrm{mol} \mathrm{TE} / \mathrm{g} \mathrm{dm})$, while the lowest ORAC value described sea buckthorn extract (70.74 $\mu \mathrm{mol} \mathrm{TE} / \mathrm{g} \mathrm{dm}$ ). According to Lu and Foo (2001) [81] rosmarinic acid derivatives considerably contribute to AC of sage. Furthermore, applied extraction method also significantly affected AC (Table 3). It can be seen that ASE contributed to the highest AC in plant extracts $(535.11 \mu \mathrm{mol} \mathrm{TE} / \mathrm{g} \mathrm{dm})$, while lower $\mathrm{AC}$ was observed in plant extracts obtained by $\mathrm{CE}$ and UAE. Higher AC was also reported in mulberry extracts obtained by ASE when compared to UAE [73].

It can be concluded that all analyzed plant extracts showed potent $\mathrm{AC}$ and differences in $\mathrm{AC}$ among plant extracts may be attributed to the content of phenolic compounds present in the extract as well as the extraction method applied. 


\section{Conclusions}

Significant variability in the phenolic composition among extracts of selected plant species [bay (Laurus nobilis L.), sage (Salvia officinalis L.) and thyme leaves (Thymus vulgaris L.), myrtle leaves and berries (Myrtus communis L.) and sea buckthorn berries (Hippophae rhamnoides L.)] was observed. The flavonoids such as FOL, FLAOL, FON, ANT and LG were the predominant phenolic groups in bay, sage and sea buckthorn, while HBA and HCA and their derivates were the most abundant in thyme and myrtle extracts. Results revealed that the most represented compounds in bay extracts were kaempferol-3-O-hexoside and quercetin-3-glucoside, while isorhamnetine-3-O-hexoside and luteolin-7-O-glucoside were the most abundant in sea buckthorn and sage extracts, respectively. In thyme and myrtle extracts HBA and its derivates were represented by 4-hydroxybenzoic and 5-Ogalloyl-quinic acid. Moreover, yields of phenolics were strongly influenced by extraction technique used. ASE showed to be the most appropriate extraction method for FOL, FON, HCA and HBA, while UAE and CE showed better efficiency in extraction of ANT and FLAOL, respectively. The results of current study proved that sage, myrtle and bay extracts obtained by ASE contain different phenolics and high AC levels and therefore possess a great potential to be used as a source of natural antioxidants in production of functional and added-value products.

Author Contributions: Conceptualization, P.Č. and S.P.; methodology, P.Č. and S.P.; formal analysis, P.C.., D.C. and D.P.; investigation, S.B., Z.Z. and M.R.; data curation, Z.Z. and I.E.G.; writing—original draft preparation, P.Č. and S.P.; writing-review and editing, S.B., M.R. and I.E.G. All authors have read and agreed to the published version of the manuscript.

Funding: This work was supported by the project "Bioactive molecules of medical plant as natural antioxidants, microbicides and preservatives" (KK.01.1.1.04.0093), co-financed by the Croatian Government and the European Union through the European Regional Development Fund-Operational Programme Competitiveness and Cohesion (KK.01.1.1.04).

Institutional Review Board Statement: Not applicable.

Informed Consent Statement: Not applicable.

Data Availability Statement: Not applicable.

Acknowledgments: Authors would like to thank Zoran Herceg for the support in providing laboratory equipment used for the experiments through the project "Equipping the Semi-Industrial Pratice Laboratory for the Development of New Food Technologies" (KK.01.1.1.02.0001) financed by the European Union.

Conflicts of Interest: The authors declare no potential financial or other interests that could be perceived to influence the outcomes of the research. No conflict, informed consent, human or animal rights applicable.

\section{References}

1. Ozcan, T.; Akpinar-Bayizit, A.; Yilmaz-Ersan, L.; Delikanli, B. Phenolics in Human Health. Int. J. Chem. Eng. Appl. 2014, 5, 393-396. [CrossRef]

2. $\quad$ Elmastas, M.; Gulcin, I.; Isildak, O.; Kufrevioglu, O.I.; Ibaoglu, K.; Aboul-Enein, H.Y. Radical scavenging activity and antioxidant capacity of bay leaf extracts. J. Iran. Chem. Soc. 2006, 3, 258-266. [CrossRef]

3. Suryakumar, G.; Gupta, A. Medicinal and therapeutic potential of Sea buckthorn (Hippophae rhamnoides L.). J. Ethnopharmacol. 2011, 138, 268-278. [CrossRef]

4. Enkhtaivan, G.; John, K.M.M.; Pandurangan, M.; Hur, J.H.; Leutou, A.S.; Kim, D.H. Extreme effects of Seabuckthorn extracts on influenza viruses and human cancer cells and correlation between flavonol glycosides and biological activities of extracts. Saudi J. Biol. Sci. 2017, 24, 1646-1656. [CrossRef] [PubMed]

5. Rezzoug, M.; Bakchiche, B.; Gherib, A.; Roberta, A.; Guido, F.; Kilincarslan, O.; Mammadov, R.; Bardaweel, S.K. Chemical composition and bioactivity of essential oils and Ethanolic extracts of Ocimum basilicum L. and Thymus algeriensis Boiss. \& Reut. from the Algerian Saharan Atlas. BMC Complement. Altern. Med. 2019, 19, 146. [CrossRef]

6. Guine, R.P.F.; Goncalves, F.J. Bioactive Compounds in Some Culinary Aromatic Herbs and Their Effects on Human Health. Mini-Rev. Med. Chem 2016, 16, 855-866. [CrossRef] 
7. Jovanovic, S.C.; Zlatkovic, B.K.; Stojanovic, G.S. Chemotaxonomic Approach to the Central Balkan Sedum Species Based on Distribution of Triterpenoids in Their Epicuticular Waxes. Chem. Biodivers. 2016, 13, 459-465. [CrossRef] [PubMed]

8. Criste, A.; Urcan, A.C.; Bunea, A.; Furtuna, F.R.P.; Olah, N.K.; Madden, R.H.; Corcionivoschi, N. Phytochemical Composition and Biological Activity of Berries and Leaves from Four Romanian Sea Buckthorn (Hippophae rhamnoides L.) Varieties. Molecules 2020, 25, 1170. [CrossRef]

9. Kabtni, S.; Sdouga, D.; Rebey, I.B.; Save, M.; Trifi-Farah, N.; Fauconnier, M.L.; Marghali, S. Influence of climate variation on phenolic composition and antioxidant capacity of Medicago minima populations. Sci. Rep. UK 2020, 10, 8293. [CrossRef]

10. Roby, M.H.H.; Sarhan, M.A.; Selim, K.A.H.; Khalel, K.I. Evaluation of antioxidant activity, total phenols and phenolic compounds in thyme (Thymus vulgaris L.), sage (Salvia officinalis L.), and marjoram (Origanum majorana L.) extracts. Ind. Crop. Prod. 2013, 43, 827-831. [CrossRef]

11. Hennia, A.; Miguel, M.G.; Nemmiche, S. Antioxidant Activity of Myrtus communis L. and Myrtus nivellei Batt. \& Trab. Extracts: A Brief Review. Medicines 2018, 5, 89. [CrossRef]

12. Kaurinovic, B.; Vastag, D. Flavonoids and phenolic acids as potential natural antioxidants. In Antioxidants; Shalaby, E., Ed.; IntechOpen: London, UK, 2019; pp. 127-146.

13. Manousi, N.; Sarakatsianos, I.; Samanidou, V. Extraction Techniques of Phenolic Compounds and Other Bioactive Compounds from Medicinal and Aromatic Plants. In Engineering Tools in the Beverage Industry; Grumezescu, A.M., Holban, A.M., Eds.; Woodhead Publishing: Cambridge, UK, 2019; Volume 3, pp. 283-314.

14. Dai, J.; Mumper, R.J. Plant Phenolics: Extraction, Analysis and Their Antioxidant and Anticancer Properties. Molecules 2010, 15, 7313-7352. [CrossRef] [PubMed]

15. Zhang, Q.W.; Lin, L.G.; Ye, W.C. Techniques for extraction and isolation of natural products: A comprehensive review. Chin. Med.-UK 2018, 13, 20. [CrossRef]

16. Handa, S.; Khanuja, S.; Longo, G.; Rakesh, D. Extraction Technologies for Medicinal and Aromatic Plants. United Nations Industrial Development Organization and the International Centre for Science and High Technology, Trieste, 2008; 260p. Available online: https:/ / www.unido.org/sites/default/files/2009-10/Extraction_technologies_for_medicinal_and_aromatic_plants_0. pdf (accessed on 30 November 2021).

17. Ameer, K.; Shahbaz, H.M.; Kwon, J.H. Green Extraction Methods for Polyphenols from Plant Matrices and Their Byproducts: A Review. Compr. Rev. Food Sci. Food 2017, 16, 295-315. [CrossRef] [PubMed]

18. Zuorro, A.; Lavecchia, R.; Medici, F.; Piga, L. Use of Cell Wall Degrading Enzymes for the Production of High-Quality Functional Products from Tomato Processing Waste. Chem. Eng. Trans. 2014, 38, 355-360. [CrossRef]

19. Xu, B.J.; Chang, S.K.C. A comparative study on phenolic profiles and antioxidant activities of legumes as affected by extraction solvents. J. Food Sci. 2007, 72, S159-S166. [CrossRef] [PubMed]

20. Azmir, J.; Zaidul, I.S.M.; Rahman, M.M.; Sharif, K.M.; Mohamed, A.; Sahena, F.; Jahurul, M.H.A.; Ghafoor, K.; Norulaini, N.A.N.; Omar, A.K.M. Techniques for extraction of bioactive compounds from plant materials: A review. J. Food Eng. 2013, 117, 426-436. [CrossRef]

21. Upadhyay, R.; Jha, A.; Singh, S.P.; Kumar, A.; Singh, M. Appropriate solvents for extracting total phenolics, flavonoids and ascorbic acid from different kinds of millets. J. Food Sci. Technol. Mys. 2015, 52, 472-478. [CrossRef]

22. Ismail, B.B.; Pu, Y.F.; Guo, M.M.; Ma, X.B.; Liu, D.H. LC-MS/QTOF identification of phytochemicals and the effects of solvents on phenolic constituents and antioxidant activity of baobab (Adansonia digitata) fruit pulp. Food Chem. 2019, 277, 279-288. [CrossRef]

23. Teo, C.C.; Tan, S.N.; Yong, J.W.H.; Hew, C.S.; Ong, E.S. Pressurized hot water extraction (PHWE). J. Chromatogr. A 2010, 1217, 2484-2494. [CrossRef] [PubMed]

24. Repajic, M.; Cegledi, E.; Kruk, V.; Pedisic, S.; Cinar, F.; Kovacevic, D.B.; Zutic, I.; Dragovic-Uzelac, V. Accelerated Solvent Extraction as a Green Tool for the Recovery of Polyphenols and Pigments from Wild Nettle Leaves. Processes $2020,8,803$. [CrossRef]

25. Elez Garofulic, I.; Zoric, Z.; Pedisic, S.; Brncic, M.; Dragovic-Uzelac, V. UPLC-MS(2) Profiling of Blackthorn Flower Polyphenols Isolated by Ultrasound-Assisted Extraction. J. Food Sci. 2018, 83, 2782-2789. [CrossRef] [PubMed]

26. Garofulic, I.E.; Kruk, V.; Martic, A.; Martic, I.; Zoric, Z.; Pedisic, S.; Dragovic, S.; Dragovic-Uzelac, V. Evaluation of Polyphenolic Profile and Antioxidant Activity of Pistacia lentiscus L. Leaves and Fruit Extract Obtained by Optimized Microwave-Assisted Extraction. Foods 2020, 9, 1556. [CrossRef] [PubMed]

27. Alara, O.R.; Abdurahman, N.H.; Ukaegbu, C.I. Extraction of phenolic compounds: A review. Curr. Res. Food Sci. 2021, 4, 200-214. [CrossRef]

28. Dobrincic, A.; Repajic, M.; Garofulic, I.E.; Tuden, L.; Dragovic-Uzelac, V.; Levaj, B. Comparison of Different Extraction Methods for the Recovery of Olive Leaves Polyphenols. Processes 2020, 8, 1008. [CrossRef]

29. Uwineza, P.A.; Waskiewicz, A. Recent Advances in Supercritical Fluid Extraction of Natural Bioactive Compounds from Natural Plant Materials. Molecules 2020, 25, 3847. [CrossRef]

30. Chaves, J.O.; de Souza, M.C.; da Silva, L.C.; Lachos-Perez, D.; Torres-Mayanga, P.C.; Machado, A.P.D.; Forster-Carneiro, T.; Vazquez-Espinosa, M.; Gonzalez-de-Peredo, A.V.; Barbero, G.F.; et al. Extraction of Flavonoids From Natural Sources Using Modern Techniques. Front. Chem. 2020, 8, 507887. [CrossRef] [PubMed] 
31. Stanojevic, L.; Stankovic, M.; Nikolic, V.; Nikolic, L.; Ristic, D.; Canadanovic-Brunet, J.; Tumbas, V. Antioxidant Activity and Total Phenolic and Flavonoid Contents of Hieracium pilosella L. Extracts. Sensors 2009, 9, 5702. [CrossRef] [PubMed]

32. Zheng, W.; Wang, S.Y. Antioxidant activity and phenolic compounds in selected herbs. J. Agric. Food Chem. 2001, 49, 5165-5170. [CrossRef] [PubMed]

33. Huang, D.J.; Ou, B.X.; Prior, R.L. The chemistry behind antioxidant capacity assays. J. Agric. Food Chem. 2005, 53, 1841-1856. [CrossRef] [PubMed]

34. Prior, R.L. Oxygen radical absorbance capacity (ORAC): New horizons in relating dietary antioxidants/bioactives and health benefits. J. Funct. Foods 2015, 18, 797-810. [CrossRef]

35. Lu, Y.R.; Foo, L.Y. Polyphenolics of Salvia-A review. Phytochemistry 2002, 59, 117-140. [CrossRef]

36. Romani, A.; Pinelli, P.; Mulinacci, N.; Vincieri, F.F.; Tattini, M. Identification and quantitation of polyphenols in leaves of Myrtus communis L. Chromatographia 1999, 49, 17-20. [CrossRef]

37. March, R.E.; Miao, X.S. A fragmentation study of kaempferol using electrospray quadrupole time-of-flight mass spectrometry at high mass resolution. Int. J. Mass Spectrom. 2004, 231, 157-167. [CrossRef]

38. Montoro, P.; Tuberoso, C.I.G.; Perrone, A.; Piacente, S.; Cabras, P.; Pizza, C. Characterisation by liquid chromatographyelectrospray tandem mass spectrometry of anthocyanins in extracts of Myrtus communis L. berries used for the preparation of myrtle liqueur. J. Chromatogr. A 2006, 1112, 232-240. [CrossRef]

39. Hossain, M.B.; Rai, D.K.; Brunton, N.P.; Martin-Diana, A.B.; Barry-Ryan, C. Characterization of Phenolic Composition in Lamiaceae Spices by LC-ESI-MS/MS. J. Agric. Food Chem. 2010, 58, 10576-10581. [CrossRef] [PubMed]

40. Pinheiro, P.F.; Justino, G.C. Structural Analysis of Flavonoids and Related Compounds-A Review of Spectroscopic Applications. Phytochem. A Glob. Perspect. Role Nutr. Health 2012, 33-56. [CrossRef]

41. Romani, A.; Campo, M.; Pinelli, P. HPLC/DAD/ESI-MS analyses and anti-radical activity of hydrolyzable tannins from different vegetal species. Food Chem. 2012, 130, 214-221. [CrossRef]

42. Barros, M.S.M.; Nascimento, A.J.; Macedo, A.F.; Ramos, J.G.G.S.; Barbosa, A.L.R. Open chaotic Dirac billiards: Weak (anti)localization, conductance fluctuations, and decoherence. Phys. Rev. B 2013, 88, 245133. [CrossRef]

43. Pop, R.M.; Socaciu, C.; Pintea, A.; Buzoianu, A.D.; Sanders, M.G.; Gruppen, H.; Vincken, J.P. UHPLC/PDA-ESI/MS Analysis of the Main Berry and Leaf Flavonol Glycosides from Different Carpathian Hippophae rhamnoides L. Varieties. Phytochem. Anal. 2013, 24, 484-492. [CrossRef] [PubMed]

44. Taamalli, A.; Iswaldi, I.; Arraez-Roman, D.; Segura-Carretero, A.; Fernandez-Gutierrez, A.; Zarrouk, M. UPLC-QTOF/MS for a rapid characterisation of phenolic compounds from leaves of Myrtus communis L. Phytochem. Anal. 2014, 25, 89-96. [CrossRef] [PubMed]

45. Carocho, M.; Barros, L.; Bento, A.; Santos-Buelga, C.; Morales, P.; Ferreira, I.C.F.R. Castanea sativa Mill. Flowers amongst the Most Powerful Antioxidant Matrices: A Phytochemical Approach in Decoctions and Infusions. Biomed. Res. Int. 2014, 2014, 232956. [CrossRef]

46. Osterc, G.; Cunja, V.; Mikulic-Petkovsek, M.; Schmitzer, V.; Stampar, F.; Bavcon, J. Foliage identification of different autochtonous common cyclamen genotypes (Cyclamen purpurascens Mill.) using various biochemical parameters. Sci. Hortic.-Amst. 2014, 173, 37-44. [CrossRef]

47. Maldini, M.; Chessa, M.; Petretto, G.L.; Montoro, P.; Rourke, J.P.; Foddai, M.; Nicoletti, M.; Pintore, G. Profiling and Simultaneous Quantitative Determination of Anthocyanins in Wild Myrtus communis L. Berries from Different Geographical Areas in Sardinia and their Comparative Evaluation. Phytochem. Anal. 2016, 27, 249-256. [CrossRef] [PubMed]

48. Sharma, Y.; Velamuri, R.; Fagan, J.; Schaefer, J.; Streicher, C.; Stimson, J. Identification and characterization of polyphenols and volatile terpenoid compounds in different extracts of garden sage (Salvia officinalis L.). Pharm. Res. 2020, 12, 149-157. [CrossRef]

49. Dias, M.I.; Barros, L.; Duenas, M.; Alves, R.C.; Oliveira, M.B.P.P.; Santos-Buelga, C.; Ferreira, I.C.F.R. Nutritional and antioxidant contributions of Laurus nobilis L. leaves: Would be more suitable a wild or a cultivated sample? Food Chem. 2014, 156, 339-346. [CrossRef]

50. Barros, L.; Alves, C.T.; Duenas, M.; Silva, S.; Oliveira, R.; Carvalho, A.M.; Henriques, M.; Santos-Buelga, C.; Ferreira, I.C.F.R Characterization of phenolic compounds in wild medicinal flowers from Portugal by HPLC-DAD-ESI/MS and evaluation of antifungal properties. Ind. Crop. Prod. 2013, 44, 104-110. [CrossRef]

51. Barboni, T.; Cannac, M.; Massi, L.; Perez-Ramirez, Y.; Chiaramonti, N. Variability of Polyphenol Compounds in Myrtus Communis L. (Myrtaceae) Berries from Corsica. Molecules 2010, 15, 7849. [CrossRef] [PubMed]

52. Pereira, P.; Cebola, M.J.; Oliveira, M.C.; Bernardo-Gil, M.G. Supercritical fluid extraction vs. conventional extraction of myrtle leaves and berries: Comparison of antioxidant activity and identification of bioactive compounds. J. Supercrit. Fluids 2016, 113, 1-9. [CrossRef]

53. Martins, N.; Barros, L.; Santos-Buelga, C.; Henriques, M.; Silva, S.; Ferreira, I.C.F.R. Evaluation of bioactive properties and phenolic compounds in different extracts prepared from Salvia officinalis L. Food Chem. 2015, 170, 378-385. [CrossRef] [PubMed]

54. Dent, M.; Dragovic-Uzelac, V.; Garofulic, I.E.; Bosiljkov, T.; Jezek, D.; Brncic, M. Comparison of Conventional and Ultrasoundassisted Extraction Techniques on Mass Fraction of Phenolic Compounds from Sage (Salvia officinalis L.). Chem. Biochem. Eng. $Q$ 2015, 29, 475-484. [CrossRef]

55. Masterova, I.; Uhrin, D.; Kettmann, V.; Suchy, V. Phytochemical Study of Salvia-Officinalis L. Chem. Pap. 1989, 43, 797-803. 
56. Wang, M.F.; Li, J.G.; Rangarajan, M.; Shao, Y.; LaVoie, E.J.; Huang, T.C.; Ho, C.T. Antioxidative phenolic compounds from sage (Salvia officinalis). J. Agric. Food Chem. 1998, 46, 4869-4873. [CrossRef]

57. Lu, Y.R.; Foo, L.Y. Flavonoid and phenolic glycosides from Salvia officinalis. Phytochemistry 2000, 55, 263-267. [CrossRef]

58. Kulisic, T.; Dragovic-Uzelac, V.; Milos, M. Antioxidant activity of aqueous tea infusions prepared from oregano, thyme and wild thyme. Food Technol. Biotechnol. 2006, 44, 485-492.

59. Dapkevicius, A.; van Beek, T.A.; Lelyveld, G.P.; van Veldhuizen, A.; de Groot, A.; Linssen, J.P.H.; Venskutonis, R. Isolation and structure elucidation of radical scavengers from Thymus vulgaris leaves. J. Nat. Prod. 2002, 65, 892-896. [CrossRef] [PubMed]

60. Sonmezdag, A.S.; Kelebek, H.; Selli, S. Characterization of aroma-active and phenolic profiles of wild thyme (Thymus serpyllum) by GC-MS-Olfactometry and LC-ESI-MS/MS. J. Food Sci. Technol. 2016, 53, 1957-1965. [CrossRef]

61. Romani, A.; Coinu, R.; Carta, S.; Pinelli, P.; Galardi, C.; Vincieri, F.F.; Franconi, F. Evaluation of antioxidant effect of different extracts of Myrtus communis L. Free Radic. Res. 2004, 38, 97-103. [CrossRef]

62. Zadernowski, R.; Naczk, M.; Czaplicki, S.; Rubinskiene, M.; Szlakiewicz, M. Composition of phenolic acids in sea buckthorn (Hippophae rhamnoides L.) berries. J. Am. Oil Chem. Soc. 2005, 82, 175-179. [CrossRef]

63. Vallverdu-Queralt, A.; Regueiro, J.; Martinez-Huelamo, M.; Alvarenga, J.F.R.; Leal, L.N.; Lamuela-Raventos, R.M. A comprehensive study on the phenolic profile of widely used culinary herbs and spices: Rosemary, thyme, oregano, cinnamon, cumin and bay. Food Chem. 2014, 154, 299-307. [CrossRef] [PubMed]

64. Kamatou, G.P.P.; Viljoen, A.M.; Steenkamp, P. Antioxidant, antiinflammatory activities and HPLC analysis of South African Salvia species. Food Chem. 2010, 119, 684-688. [CrossRef]

65. Tounekti, T.; Munne-Bosch, S.; Vadel, A.M.; Chtara, C.; Khemira, H. Influence of ionic interactions on essential oil and phenolic diterpene composition of Dalmatian sage (Salvia officinalis L.). Plant Physiol. Biochem. 2010, 48, 813-821. [CrossRef]

66. Sarais, G.; D’Urso, G.; Lai, C.; Pirisi, F.M.; Pizza, C.; Montoro, P. Targeted and untargeted mass spectrometric approaches in discrimination between Myrtus communis cultivars from Sardinia region. J. Mass Spectrom. 2016, 51, 704-715. [CrossRef] [PubMed]

67. Scorrano, S.; Lazzoi, M.R.; Mergola, L.; di Bello, M.P.; del Sole, R.; Vasapollo, G. Anthocyanins Profile by Q-TOF LC/MS in Myrtus communis Berries from Salento Area. Food Anal. Method 2017, 10, 2404-2411. [CrossRef]

68. Siracusa, L.; Napoli, E.; Tuttolomondo, T.; Licata, M.; La Bella, S.; Gennaro, M.C.; Leto, C.; Sarno, M.; Sperlinga, E.; Ruberto, G. A Two-Year Bio-Agronomic and Chemotaxonomic Evaluation of Wild Sicilian Myrtle (Myrtus communis L.) Berries and Leaves. Chem. Biodivers. 2019, 16, e1800575. [CrossRef] [PubMed]

69. Fadda, A.; Mulas, M. Chemical changes during myrtle (Myrtus communis L.) fruit development and ripening. Sci. Hortic.-Amst. 2010, 125, 477-485. [CrossRef]

70. Giergielewicz-Mozajska, H.; Dabrowski, L.; Namiesnik, J. Accelerated Solvent Extraction (ASE) in the analysis of environmental solid samples-Some aspects of theory and practice. Crit. Rev. Anal. Chem. 2001, 31, 149-165. [CrossRef]

71. Khoddami, A.; Wilkes, M.A.; Roberts, T.H. Techniques for Analysis of Plant Phenolic Compounds. Molecules 2013, 18, 2328. [CrossRef]

72. Asofiei, I.; Calinescu, I.; Trifan, A.; David, I.G.; Gavrila, A.I. Microwave-Assisted Batch Extraction of Polyphenols from Sea Buckthorn Leaves. Chem. Eng. Commun. 2016, 203, 1547-1553. [CrossRef]

73. Yang, J.F.; Ou, X.Q.; Zhang, X.X.; Zhou, Z.Y.; Ma, L.Y. Effect of Different Solvents on the Measurement of Phenolics and the Antioxidant Activity of Mulberry (Morus atropurpurea Roxb.) with Accelerated Solvent Extraction. J. Food Sci. 2017, 82, 605-612. [CrossRef] [PubMed]

74. Bouaoudia-Madi, N.; Boulekbache-Makhlouf, L.; Madani, K.; Silva, A.M.S.; Dairi, S.; Oukhmanou-Bensidhoum, S.; Cardoso, S.M. Optimization of Ultrasound-Assisted Extraction of Polyphenols from Myrtus communis L. Pericarp. Antioxidants $2019,8,205$. [CrossRef]

75. Cai, Z.; Qu, Z.Q.; Lan, Y.; Zhao, S.J.; Ma, X.H.; Wan, Q.; Jing, P.; Li, P.F. Conventional, ultrasound-assisted, and accelerated-solvent extractions of anthocyanins from purple sweet potatoes. Food Chem. 2016, 197, 266-272. [CrossRef] [PubMed]

76. Pereira, P.; Cebola, M.J.; Oliveira, M.C.; Gil, M.G.B. Antioxidant capacity and identification of bioactive compounds of Myrtus communis L. extract obtained by ultrasound-assisted extraction. J. Food Sci. Technol. Mys. 2017, 54, 4362-4369. [CrossRef] [PubMed]

77. Sulniute, V.; Ragazinskiene, O.; Venskutonis, P.R. Comprehensive Evaluation of Antioxidant Potential of 10 Salvia Species Using High Pressure Methods for the Isolation of Lipophilic and Hydrophilic Plant Fractions. Plant Food Hum. Nutr. 2016, 71, 64-71. [CrossRef] [PubMed]

78. Babou, L.; Hadidi, L.; Grosso, C.; Zaidi, F.; Valentao, P.; Andrade, P.B. Study of phenolic composition and antioxidant activity of myrtle leaves and fruits as a function of maturation. Eur. Food Res. Technol. 2016, 242, 1447-1457. [CrossRef]

79. Kratchanova, M.; Denev, P.; Ciz, M.; Lojek, A.; Mihailov, A. Evaluation of antioxidant activity of medicinal plants containing polyphenol compounds. Comparison of two extraction systems. Acta Biochim. Pol. 2010, 57, 229-234. [CrossRef] [PubMed]

80. Tkacz, K.; Wojdylo, A.; Turkiewicz, I.P.; Bobak, L.; Nowicka, P. Anti-Oxidant and Anti-Enzymatic Activities of Sea Buckthorn (Hippophae rhamnoides L.) Fruits Modulated by Chemical Components. Antioxidants 2019, 8, 618. [CrossRef]

81. Lu, Y.R.; Foo, L.Y. Antioxidant activities of polyphenols from sage (Salvia officinalis). Food Chem. 2001, 75, 197-202. [CrossRef] 